\title{
ASSESSMENT OF LIFE QUALITY IN PATIENTS WITH STAGE IIB-IIIB SQUAMOUS CELL CERVICAL CANCER RECEIVING PACLITAXEL CISPLATIN CHEMOTHERAPY REGIMEN BY EORTC QLQ-C30 QUESTIONNAIRE IN SANGLAH HOSPITAL DENPASAR
}

\author{
RINI NOVIYANI ${ }^{*}$, PUTU AYU INDRAYATHI ${ }^{2}$, I NYOMAN GEDE BUDIANA ${ }^{3}$, KETUT SUWIYOGA ${ }^{3}$, KETUT TUNAS ${ }^{4}$ \\ 1Department of Pharmacy, Faculty of Mathematics and Natural Sciences, Udayana University, Postal Code 80361, Bali, \\ Indonesia, ${ }^{2}$ Program Study of Public Health, Faculty of Medicine, Udayana University, Postal Code 80234, Bali, Indonesia, ${ }^{3}$ Department \\ Obstetrics and Gynecology, Faculty of Medicine, University of Udayana, Postal Code 80234, Bali, Indonesia, ${ }^{4}$ Department of Public Health, \\ Faculty of Health Sciences, Science and Technology, University of Dhyana Pura, Postal Code 80361, Bali, Indonesia \\ Email: rini.noviyani@gmail.com
}

Received: 09 Feb 2017 Revised and Accepted: 31 Mar 2017

\section{ABSTRACT}

Objective: Cervical cancer was the prominent cause of women's death in developing states. Decrease in life quality was often encountered by patients with cervical cancer in advanced stages. One treatment method of cervical cancer at Sanglah Hospital was using paclitaxel cisplatin chemotherapy. Information on cervical cancer patient's life quality who received paclitaxel cisplatin chemotherapy was still limited, so research was required to observe cervical cancer patients' life quality before the first and after the sixth paclitaxel cisplatin chemotherapy regimen.

Methods: Observational study with prospective case study design was undertaken at the Polyclinic of Obstetrics and Gynecology Sanglah Hospital from January to August 2016. Sampling was conducted before chemotherapy I and after chemotherapy VI using consecutive sampling method. The EORTC QLQ C30 questionnaires were completed by the patients before chemotherapy I and after chemotherapy VI. Patients' life quality who had received paclitaxel cisplatin chemotherapy were assessed with 15 domains in EORTC QLQ C30 questionnaire. The data obtained were processed with STATA ${ }^{\circledR}$ version 14 and analysed using paired t test and Wilcoxon test with a confidence level of $95 \%$.

Results: The number of samples used in this study was 7 patients who received paclitaxel cisplatin chemotherapy. The results of the analysis showed that there were differences in cervical cancer patients' life quality who had received paclitaxel cisplatin regimen chemotherapy before chemotherapy I and after chemotherapy VI with the result of p-value is 0.0005 .

Conclusion: There was a significant decrease in the value of cervical cancer patients' life quality who received paclitaxel cisplatin chemotherapy before chemotherapy I and after chemotherapy VI.

Keywords: Cervical cancer, Chemotherapy, Paclitaxel cisplatin, Quality of life, EORTC QLQ C30 questionnaire

(C) 2017 The Authors. Published by Innovare Academic Sciences Pvt Ltd. This is an open access article under the CC BY license (http://creativecommons.org/licenses/by/4.0/] DOI: http://dx.doi.org/10.22159/ijpps.2017v9i5.17621

\section{INTRODUCTION}

Cervical cancer is a gynaecological illness that has been the foremost cancer-related cause of death in developing states. In Indonesia, it is estimated that 15,000 new cases of cervical cancer occur annually. Meanwhile, at Sanglah Hospital Denpasar, Bali, there has been an increase in the number of patients treated for cervical cancer. Most of the cervical cancer patients treated at Sanglah Hospital were cervical cancer patients with advanced stage, which ranged from the IIB-IIIB stage. At this stage, the most common symptoms encountered by patients include bleeding outside the regular menstruation cycle, excessive and odorous leucorrhoea, lower abdominal pain or pelvic cramp and pain or complication during urination [1]. These symptoms could affect the patients' daily activities that would eventually lead to the deterioration of patients' life quality. Cervical cancer patients with advanced stage are generally treated with combined regimen chemotherapy [2]. The regimen used in chemotherapy for cervical cancer with an IIB-IIIB stage at Sanglah Hospital is paclitaxel cisplatin combined regimens. Based on the fixed procedure at Sanglah Hospital, the paclitaxel cisplatin is provided as much as 6 cycles [3]. Chemotherapy is part of the methods provided in order to increase the life quality and to prolong the cervical cancer patients' life expectancy. However, this particular chemotherapy would also cause some side effects such as myelosuppression (anemia, leucopenia, and thrombocytopenia), nausea, mucous membrane ulceration and alopecia [4] that could exacerbate the patients' condition and thus deteriorating the patients' life quality. Therefore, this research is intended to determine the patients' life quality before and after undergoing the six cycle chemotherapy.

The survey of patients' life quality could utilize the EORTC QLQ C30 questionnaire. This questionnaire consists of 30 questions that have been put into 15 domains. These domains could be used as a validated tool for measuring the life quality of gynaecological cancer patients at Sanglah Hospital [5].

Based on the essential data and the information about life quality, research is necessary to determine the cervical cancer patients' life quality before and after six cycle paclitaxel cisplatin chemotherapy at Sanglah Hospital, Denpasar by utilizing the EORTC QLQ C30 questionnaire.

\section{MATERIALS AND METHODS}

\section{Methods}

This research was performed at Sanglah Hospital, Denpasar from January until August 2016. The research had obtained the ethical clearance number 1895/UN.14.2/litbang/2015 from Udayana Faculty of Medicine Research Ethic Commission/Sanglah Hospital, Denpasar. The research of life quality in squamous cell carcinoma cervical cancer patients who had undergone paclitaxel cisplatin regimen chemotherapy was conducted by using observational study with a prospective case study design. This method was carried out by following the patients starting from cycle I chemotherapy until cycle VI chemotherapy with a three-week gap within every cycle. Patients were selected based with consecutive sampling method conducted at Sanglah Hospital, Denpasar towards stage IIB-IIIB cervical cancer patients. The inclusion criteria consisted of new patients with squamous cell carcinoma cervical cancer stage IIB-IIIB, patients that were willing to participate in the research by filling out the informed consent, patients that underwent paclitaxel cisplatin chemotherapy, and patients that could go through the whole 
chemotherapy cycles from the cycle I until cycle VI. And the exclusion criteria consisted of patients whose progress could not be followed up due to specific circumstances such as death, financial constraint, and loss-to-follow-up.

The questionnaire was filled out one week prior to cycle I chemotherapy and one week after patients had completed chemotherapy cycle VI. All the data regarding the patients' life quality prior to chemotherapy cycle I until the completion of chemotherapy cycle VI was gathered by using the EORTC QLQ C30 questionnaire that had been translated into the Indonesian language [5] and had been validated for patients at Sanglah Hospital, Denpasar, Bali [6]. EORTC QLQ C30 questionnaire consisted of 30 questions that had been categorised into 15 domains that consisted of overall life quality function, physical function, role function, emotional function, cognitive function, social function, fatigue symptoms, nausea symptoms, pain symptoms, dyspnea symptoms, insomnia symptoms, loss of appetite symptoms, constipation symptoms, diarrhea symptoms, and financial constraint symptoms.

Next, the acquired data were processed with STATA ${ }^{\circledR}$ version 14 and undergone normality test using the Shapiro-Wilk test. Then the data were analysed by using paired $t$ differential tests for data with normal distribution, and the Wilcoxon test for data with abnormal distribution as well as data with a $95 \%$ confidence level. A significant difference in life quality data before cycle I and after the cycle VI paclitaxel cisplatin regimen chemotherapy in patients would be marked with $\mathrm{p}<0.05$ value.

\section{RESULTS}

Table 1: Patients' characteristics who underwent paclitaxel cisplatin chemotherapy regimen

\begin{tabular}{|c|c|c|}
\hline Variables & Paclitaxel cisplatin (n=7) & Percentage (\%) \\
\hline \multicolumn{3}{|l|}{ Age (years) } \\
\hline $26-35$ & 1 & 14.28 \\
\hline $36-45$ & 3 & 42.85 \\
\hline $46-55$ & 2 & 28.57 \\
\hline $56-65$ & 1 & 14.28 \\
\hline \multicolumn{3}{|l|}{ Gender } \\
\hline Male & 0 & 0 \\
\hline Female & 7 & 100 \\
\hline \multicolumn{3}{|l|}{ Status } \\
\hline Married & 7 & 100 \\
\hline Unmarried & 0 & 0 \\
\hline \multicolumn{3}{|l|}{ Employment } \\
\hline Work & 6 & 85.71 \\
\hline Not work & 1 & 14.29 \\
\hline \multicolumn{3}{|l|}{ Ethnic } \\
\hline Balinese & 3 & 42.86 \\
\hline Javanese & 1 & 14.28 \\
\hline Other & 3 & 42.86 \\
\hline \multicolumn{3}{|l|}{ Stage of cancer } \\
\hline IIB & 0 & 0 \\
\hline IIIB & 7 & 100 \\
\hline \multicolumn{3}{|l|}{ Histologycal type } \\
\hline Squamous cell & 7 & 100 \\
\hline Adenocarcinoma & 0 & 0 \\
\hline \multicolumn{3}{|l|}{ Level of study } \\
\hline Not school & 1 & 14.28 \\
\hline Elementary school & 4 & 57.16 \\
\hline Junior high school & 1 & 14.28 \\
\hline Senior high school & 1 & 14.28 \\
\hline
\end{tabular}

$\mathrm{n}=$ number of patients, 7 patients were assessed, Based on the table above, there were 7 patients obtained as samples. All of them were married were diagnosed with squamous cell type cervical cancer during stage IIIB and had the age range from between 26 until $65 \mathrm{y}$ old.

Table 2: Difference of cervical cancer patients' life quality that underwent paclitaxel cisplatin regimen chemotherapy with the paired t-test

\begin{tabular}{lll}
\hline Chemotherapy $(\mathbf{n}=\mathbf{7})$ & Mean value of life quality & p-value \\
\hline Prior to Chemotherapy I & $52.89+5.28$ & $0.0005^{*}$ \\
After Chemotherapy VI & $60.71+12.58$ & \\
\hline
\end{tabular}
$60.71+12.58$

$\mathrm{n}=$ number of patients. ${ }^{*}$ Statistically significant. Quality of life are expressed as mean values with plus-minus values as standard deviation, Based on table 2, there was an increase in the value of mean from 52.89 to 60.71 after chemotherapy VI with the value of $p=0.0005$.

Table 3: The domain values of EORTC QLQ-C30 questionnaire in patients that underwent paclitaxel cisplatin regimen chemotherapy with the paired t-test

\begin{tabular}{llll}
\hline Domain (n=7) & Mean value, prior to chemotherapy I & Mean value, After chemotherapy VI & p-value \\
\hline Overall life quality & $9.14+1.57$ & $9.86+1.21$ & 0.73 \\
Physical function & $6.71+2.36$ & $14.14+4.02$ & $5.86+1.46$ \\
Role function & $2.43+0.78$ & $8.43+2.88$ & $0.0012^{*}$ \\
Emotional function & $6+1.63$ & $4.29+1.49$ & $0.006^{*}$ \\
Cognitive function & $2.43+0.53$ & $10.43+1.72$ & 0.0754 \\
Fatigue & $5.86+2.12$ & $10.43+1.72$ \\
Pain & $4.14+1.46$ & $2.57+0.98$ & $0.0062^{*}$ \\
Insomnia & $2.57+1.27$ & $2.29+1.11$ & $0.0002^{*}$ \\
Constipation & $1.43+0.79$ & 1.00 \\
\hline
\end{tabular}

$\mathrm{n}=$ number of patients. ${ }^{*}$ Statistically significant. Data are expressed as mean values with plus-minus values as standard deviation 
Based on table 3 above, it was shown that the domains with the value of $\mathrm{p}<0.05$ and an increase in the value of the mean were a physical function, role function, cognitive function, fatigue, and pain. Domains with the value of $p<0.05$ and a decrease in the value of the mean were none. Domains with the value of $\mathrm{p}<0.05$ and no change in the value of the mean were none. On the contrary, domains with the value of $p>0.05$ and an increase in the value of the mean were the overall life quality, emotional function, and constipation. Domains with the value of $p>0.05$ and $a$ decrease in the value of the mean were none. Domain with the value of $p>0.05$ and no change in the value of the mean was insomnia.

Table 4: The domain values of EORTC QLQ-C30 questionnaire in patients that underwent paclitaxel cisplatin regimen chemotherapy with the Wilcoxon test

\begin{tabular}{|c|c|c|c|}
\hline Domain $(n=7)$ & $\begin{array}{l}\text { Mean value of life quality prior to } \\
\text { chemotherapy I }\end{array}$ & $\begin{array}{l}\text { Mean value of life quality after } \\
\text { chemotherapy VI }\end{array}$ & $\begin{array}{l}\text { Wilcoxon } \\
\text { p-value }\end{array}$ \\
\hline Social & $2.14+0.38$ & $3.29+0.76$ & $0.0194 *$ \\
\hline Dyspnea & $1.14+0.38$ & $1.88+1.07$ & 0.1605 \\
\hline Nausea & $2.57+1.13$ & $6.43+1.81$ & $0.0208 *$ \\
\hline Loss of appetite & $1.29+0.49$ & $3.29+1.11$ & $0.0194 *$ \\
\hline Diarrhea & $1.29+0.49$ & $1.43+0.53$ & 0.5637 \\
\hline Financial constraint & $1.86+0.69$ & $3.14+0.69$ & $0.0201^{*}$ \\
\hline
\end{tabular}

n= number of patients. *Statistically significant. Data are expressed as mean values with plus-minus values as standard deviation

Based on table 4 above, it was shown that the domains with the value of $\mathrm{p}<0.05$ and an increase in the value of the mean were social, nausea, loss of appetite, and financial constraint. Domains with the value of $\mathrm{p}<0.05$ and a decrease in the value of the mean were none. Domains with the value of $p<0.05$ and no change in the value of the mean were none. On the contrary, a domain with the value of $p>0.05$ and an increase in the value of the mean was dyspnea and diarrhoea Domains with the value of $p>0.05$ and a decrease in the value of the mean were none. Domain with the value of $p>0.05$ and a decrease in the value of the mean were none

\section{DISCUSSION}

Table 1 shows that the number of samples in this research is seven patients with the range of age between 26-65 y and married. All seven patients were diagnosed with squamous cell carcinoma cervical cancer in the advanced stages of IIIB. Patients often got their treatment during later stages because there were no early symptoms of cervical cancer shown during the early stages. Patients who came for treatment during the advanced stages had also triggered problems in optioning for effective therapeutic method [4] That's why early detection as a preventive action is necessary in order to prevent cervical cancer.

Patients' life quality on this research was measured from two indicators. They were the value of mean and the value of p. Based on the value of the mean, a decrease in its value equalled to an increase in life quality. An increase in the value of mean equalled to a decrease in life quality. And if there was no constant value of mean before and after chemotherapy, it could be possible to conclude that the life quality remained the same. Secondly, based on the value of $p$, the value of $p<0.05$ equalled to a significant difference statistically. And the value of $p>0.05$ equalled to no significant difference.

Based on those two factors, it could be implied that there was a significant decrease in stage IIB-IIIB squamous cell carcinoma cervical cancer patients' life quality before and after chemotherapy I and VI respectively if they had undergone paclitaxel cisplatin chemotherapy. This conclusion was derived from the result set out in table 2. This research had also analysed patients' life quality more detail based on the domains available in EORTC QLQ-C30 questionnaire. The result was given in table 3 and table 4 . And here is the analysis.

The decrease of cervical cancer patients' life quality could significantly be found in the domains of physical function, role function, cognitive function, fatigue, pain, social, nausea, loss of appetite, and financial constraint.

There was a major decrease on the physical function domain from prior to undergoing cycle I chemotherapy to after undergoing chemotherapy cycle VI. The decrease in this domain existed since patients had complained about physical function disorder such as difficulty in lifting heavy objects, walking for both near and far distance, as well as doing private activities like urinating, eating or wearing clothes. These are the symptoms of peripheral neuropathy brought about by chemotherapy [7]. Combined paclitaxel and cisplatin chemotherapy could trigger significant neurotoxicity [8] Neurotoxicity causes the decrease in daily physical activities. The most affected domains included physical function, role function, fatigue, and pain [9]. Peripheral neuropathy induced chemotherapy could aggravate and limit daily activities and thus has a negative effect towards patients' life quality [10].

In the domain of role function, there was a major decrease in life quality. The decrease of role functions complained by the patients who had undergone 6 cycles of chemotherapy included being unable to cook, wash, clean the house or even do their hobbies such as watching television that was regularly done before chemotherapy. The decrease in role function parameter based on EORTC QLQ C30 questionnaire could be seen not only from limitation while working or doing daily activities but also from limitation while doing hobbies [6]. This decrease in role function could increase the burdens for women who survived through chemotherapy because women had the primary responsibilities of taking care of the families [11].

In the domain of the cognitive function, there was a major decrease in patients' life quality. Cognitive disorder experienced by patients after undergoing chemotherapy included difficulty in remembering things as well as in concentrating while both reading and watching television. Research shows that the use of cisplatin in chemotherapy would cause myelosuppression that leads to cognitive function disorder [12]. Another research shows that chemotherapy is closely linked to cognitive function disorders that include short term and long term memory loss, the lack of focus or attention, and difficulty in learning something new. The mechanism of chemotherapy related to cognitive functions is demyelination, microvascular injury, and intracranial inflammatory response [13].

In the domain of fatigue symptoms, there was a major decrease in life quality. Fatigue symptoms experienced by patients included weakened bodies and exhaustion so that they need to take a rest for one week after undergoing the six cycles of chemotherapy. National Comprehensive Cancer Network (2009) states that approximately 70\%-100\% cancer patients experience from exhaustion [14]. Fatigue is considered as bodily exhaustion, the desire to reduce activities, the decreasing motivation or mental exhaustion. Fatigue could be caused by dysregulation in the physiological and biochemical system. Another factor contributing towards the occurrence of fatigue includes anemia, cachexia, and depression [15]. 
In the domain of pain symptoms, there was a major decrease in life quality. This happened because patients had experienced severe pain in both abdominal and waist areas after going through six cycles of chemotherapy. Pain is part of the problems experienced frequently by advanced stage cervical cancer patients as the consequence of tumor cells' infiltration of nerve fibre and other causes triggered by further metastases [4]. The pain experienced by the patients after undergoing six cycles of chemotherapy could be caused by the agent used in chemotherapy. Chemotherapy agents that are categorised as taxane and platinum could cause neuropathic pain syndrome. The side effects usually manifest in the form of sensory dysfunction and extreme pain [16].

In the domain of the social function, there was a major decrease in life quality. Social functions were affected by a physical condition or medical therapy that could affect shared activities in society [6]. The decrease in life quality towards social function domain happened because the patients were still experiencing the side effects of chemotherapy, such as nausea, fatigue, and physical function disorder that had been hampering the patients' ability to engage in social activities. In addition, another side effect like hair loss or alopecia had caused the patients to shy away from social environments or reducing social activities which in turn had led to the decrease in their social function [17]. In the nausea domain, there was a major decrease in life quality. It is due to the side effects of cisplatin use as a chemotherapy agent. According to National Comprehensive Cancer Network (2009), cisplatin was one of the chemotherapy regimens that could trigger side effect like extreme nausea [14]. Another research also shows that patients who underwent paclitaxel cisplatin chemotherapy could experience from significant nausea side effect $[18,8]$.

About the loss of appetite domain, there was a major decrease in life quality. Patients would usually experience from the loss of appetite for one week after chemotherapy. The use of chemotherapy as medicine could decrease patients' appetite through the brains' chemoreceptor that could lead to nausea and vomiting that resulted in anorexia [19]. Cisplatin possesses side effects that include digestive disorder like nausea, diarrhoea, flatulence after eating, whitened tongue and tastes sensory disorder [20]. These side effects could prompt patients to lose their appetite and thus led to the decrease of cervical cancer patients' life quality.

In the financial constraint domain, there was a major decrease in life quality. Depending on the research of Park et al. (2007) that was carried out to measure cancer patients' life quality, it was concluded that financial constraint domain is one of the domains with major decrease and therefore affects the patients' life quality [21]. Research shows that cancer-related financial constraint could be prompted by the decrease in work productivity, low income and additional financial expense during chemotherapy. This financial constraint relates to both anxiety and depression suffered by cancer patients and therefore reduces patients' life quality [22]. There was not any significant decrease in cervical cancer patients' life quality on the domains of overall life quality, emotional function, constipation, dyspnea and diarrhoea.

In the overall life quality domain, the decrease of life quality was triggered due to the improvement of patients' life quality since the symptoms like bleeding, leucorrhoea, and pain had begun to lessen. The overall life quality had a meaningful link with the stage of cervical cancer. Overall life quality was higher in stages I, II, and III compared to stage IV [23]. Research by Perwitasari (2009) shows the same result of overall life quality, in which it shows how the decrease in life quality is not significant after going through cisplatin or its combination chemotherapy [24].

In the overall life quality domain, the decrease of life quality was triggered due to the improvement of patients' life quality since the symptoms like bleeding, leucorrhoea, and pain had begun to lessen. The overall life quality had a meaningful link with the stage of cervical cancer. Overall life quality was higher in stages I, II, and III compared to stage IV [23]. Research by Perwitasari (2009) shows the same result of overall life quality, in which it shows how the decrease in life quality is not significant after going through cisplatin or its combination chemotherapy [24].
In the overall life quality domain, the decrease of life quality was triggered due to the improvement of patients' life quality since the symptoms like bleeding, leucorrhoea, and pain had begun to lessen. The overall life quality had a meaningful link with the stage of cervical cancer. Overall life quality was higher in stages I, II, and III compared to stage IV [23]. Research by Perwitasari (2009) shows the same result of overall life quality, in which it shows how the decrease in life quality is not significant after going through cisplatin or its combination chemotherapy [24]. In the dyspnea domain, the decrease in life quality was not significant. One of the side effects from chemotherapy that could lead to the decrease of patients' life quality was the occurrence of dyspnea symptoms [29]. In this research, patients complained about experiencing dyspnea after undergoing chemotherapy for six cycles but it was not significant. Another research also shows that there is a decrease in patients' life quality on dyspnea domain after undergoing paclitaxel cisplatin chemotherapy for three cycles [30].

In the diarrhoea domain, patients complained about experiencing from diarrhoea before and after going through paclitaxel cisplatin chemotherapy for six cycles.

However, it was not significant in this research. The use of medicines for chemotherapy could prompt a change in the intestines' normal flora composition that could lead to diarrhoea [31]. One of the side effects of cisplatin chemotherapy is diarrhoea [20]. Diarrhoea is the main toxicity experienced by cervical cancer patients undergoing weekly cisplatin and paclitaxel chemoradiation [32].

However, in this research, diarrhoea domain did not show a difference in cervical cancer patients' life quality after undergoing six cycles of chemotherapy.

In this research, there were patients with a constant but not significant life quality domain before chemotherapy I and after chemotherapy VI. This could be found only on insomnia domains.

In the insomnia domain, there was neither significant increase nor decrease in life quality. This happened because the symptoms experienced by patients had started to lessen after going through chemotherapy. Another factor was because the patients had started to be able to accept their medical condition and thus they had started to feel calm. This led to the decrease of insomnia experienced prior to chemotherapy.

In this research, out of all seven samples obtained, there was no patient with an increase of life quality either significant or not significant. There was also no patient with a significant constant life quality.

\section{CONCLUSION}

There are differences in the value of patients' life quality before chemotherapy I and after chemotherapy VI. The significant decrease in cervical cancer patients' life quality after undergoing six cycles of paclitaxel cisplatin regimen chemotherapy could be seen in the domain of the physical function, role function, fatigue, pain, social, nausea, loss of appetite, and financial constraint. The insignificant decrease in cervical cancer patients' life quality after undergoing six cycles of paclitaxel cisplatin regimen chemotherapy could be seen in the domain of overall life quality, emotional function, constipation, dyspnea and diarrhea. The domains that have constant but insignificant in terms of cervical cancer patients' life quality after undergoing six cycles of paclitaxel cisplatin regimen chemotherapy is insomnia.

\section{Limitations}

This study was carried out with a limited number of patients who could finish six cycles of chemotherapy at Sanglah Hospital, Denpasar. This study only covered patients in Sanglah Hospital, Denpasar, for a limited period of time and therefore cannot be extrapolated to other regions in Indonesia. To arrive at an evidencebased conclusion, multicentre studies with a larger population are required.

\section{ACKNOWLEDGEMENT}

The Authors thank Professor Hasbullah Thabrany, Dr. PH and Professor Andrijono, Sp. OG for their valuable feedbacks during the research. The 
Authors also thank Ministry of Research, Technology and Higher Education of The Republic of Indonesia for funding this research.

\section{AUTHOR CONTRIBUTION}

As a Principal investigator, Rini Noviyani had the responsibility to design the study, develop the methodology, collect data, monitor data collection, write statistical analysis plan, analysed the data, interpreted data, draft and revise the paper. Putu Ayu Indrayathi had the responsibility to do data collection, monitor data, draft and revised the paper. Both I Nyoman Gede Budiana and Ketut Suwiyoga had the responsibilities to develop the methodology and collect data. Ketut Tunas was responsible to design statistical analysis plan and analys the data.

\section{CONFLICT OF INTERESTS}

Authors declare no conflict of interest

\section{REFERENCES}

1. Fitriana NA, Tri KA. Cervical cancer patient's life quality undergoing radiotherapy treatment. Clin Psychol Mental Health J 2012;1:147-53.

2. Saito I, Ryo K, Haruhiko F, Taro S, Katsumata N, Konishi I, et al. Phase III trial of paclitaxel plus carboplatin versus paclitaxel plus cisplatin in stage IVB, persistent or recurrent cervical cancer: gynecologic cancer study group/japan clinical oncology group study (JCOG0505). Japan J Clin Oncol 2010;40:90-3.

3. Medical Committee. Fixed procedures of cervical cancer chemotherapy. Denpasar: Sanglah Hospital; 2004.

4. Aziz F, Andrijono, Saifudin BA. Oncology gynaecology. Jakarta: Yayasan Bina Pustaka Sarwono Prawirohardjo; 2010.

5. Noviyani R, Tunas K, Indrayathi A, Budiana GN. Validity test and EORTC QLQ C-30 reliable questionnaire to measure gynaecology cancer patients' life quality in sanglah hospital Denpasar. Indonesian Pharm Clin J 2016;5:106-14.

6. Perwitasari DA, Atthobari J, Dwiprahasto I, Hakimi M, Gelderblom $\mathrm{H}$, Putter $\mathrm{H}$, et al. Translation and validation of EORTC QLQ-C30 into an Indonesian version for cancer patients in Indonesia. Japan J Clin Oncol 2011;41:519-29.

7. Polomano RC, Farrar JT. Pain and neuropathy in cancer survivors. surgery, radiation, and chemotherapy can cause pain: research could improve its detection and treatment. Am J Nurs 2006;106 Suppl 3:39-47.

8. Joseph S, Pradeep S, Jayakumar KL. A prospective comparative study of the toxicity profile in a patient receiving cisplatinpaclitaxel vs carboplatin-paclitaxel in advanced ovarian cancer. Int J Med Phar Sci 2015;6:1-5.

9. Greimel ER, Bjelic-Radisic V, Pfisterer J, Hilpert F, Daghofer F, duBois A. Randomized study of the Arbeitsgemeinschaft gynaekologische oncology ovarian cancer study group comparing the quality of life in patients with ovarian cancer treated with cisplatin/paclitaxel versus carboplatin/paclitaxel. J Clin Oncol 2006;24:579-86.

10. Mols FT, Lemmens BV, Hurk CJ, Vreugdenhil G, Poll-Franse LV. Chemotherapy-induced neuropathy and its association with quality of life among 2-to 11-year colorectal cancer survivors: results from the population-based profiles registry. J Clin Oncol 2013;31:1-10.

11. Nie SX, Gao CQ. Health behaviours and quality of life in chinese survivors of cervical cancer: a retrospective study. OncoTargets Ther 2014;7:627-32.

12. Barabas K, Milner R, Lurie D, Adin C. Cisplatin: a review of toxicities and therapeutic applications. Vet Comp Oncol 2008;6:1-18.

13. Westin SN, Sun CC, Tung CS, Lacour RA, Meyer LA, Urbauer DL, et al. Survivors of gynecologic malignancies: impact of treatment on health and well-being. J Cancer Survivorship 2015;10:261-70.

14. National Comprehensive Cancer Network (NCCN). Clinical practice guidelines in oncology: Cancer-related fatigue. NCCI; 2009.

15. Ryan JL, Carroll JK, Ryan EP, Mustian KM, Fiscella K, Morrowb GR. Mechanisms of cancer-related fatigue. Oncologist 2007;12 Suppl 1:22-34.
16. Golan-Vered Y, Pud D. Chemotherapy-induced neuropathic pain and its relation to cluster symptoms in breast cancer patients treated with paclitaxel. Pain Practice 2013;13:46-52.

17. Luanpitpong S, Rojanasakul Y. Chemotherapy-induced alopecia topics in cancer survivorship. Europe: InTech Europe; 2012. Available from: http://www.intechopen.com/books/topics-incancer-survivorship/chemotherapy-induced-alopecia [Last accessed on 10 Jan 2017].

18. Kitagawa R, Katsumata N, Shibata T, Kamura T, Kasamatsu T, Nakanishi T, et al. Paclitaxel plus carboplatin versus paclitaxel plus cisplatin in metastatic or recurrent cervical cancer: the open-label randomised phase III Trial JCOG0505. J Clin Oncol 2015;33:1-7.

19. Varsha S, Sneharika L, Amulya B, Sangram V. A prospective study on clinical evaluation, treatment pattern and adverse effects of anticancer drugs in various gynaecological cancer patients. Asian J Pharm Clin Res 2015;8:125-31.

20. Astolfi L, Ghiselli S, Guaran V, Chicca M, Simoni E, Olivetto E, et al. Correlation of adverse effects of cisplatin administration in patients affected by solid tumours: a retrospective evaluation. Oncol Rep 2013;29:1285-92.

21. Park SY, Bae DS, Nam JH, Park CT, Cho CH, Lee JM, et al. Quality of life and sexual problems in disease-free survivors of cervical cancer compared with the general population. Cancer 2007;110:2176-25.

22. Fenn KM, Evans SB, McCorkle R, DiGiovanna MP, Pusztai L, DPhil, et al. Impact of the financial burden of cancer on survivors' quality of life. J Oncol Practice 2014;10:332-9.

23. Azmawati MN, Najibah E, Hatta MD, Norfazilah A. Quality of life by stage of cervical cancer among malaysian patients. Asian Pac J Cancer Prev 2014;15:5283-6.

24. Perwitasari DA. Quality of life measurement in cancer patients before and after chemotherapy with EORTC QLQ-C30 in RSUP Dr. Sardjito Yogyakarta. Indonesian J Pharm 2009;20:68-72.

25. European Society for Medical Oncology (ESMO). Handbook of cancer: diagnosis and treatment. USA: Informa Healthcare, Inc; 2009. Available from: http://oncologypro.esmo.org/ Publications/ Handbooks/Cancer-Diagnosis-and-TreatmentEvaluation [Last accessed on 10 Jan 2017]

26. Stabile C, Gunn A, Sonoda Y, Carter J. Emotional and sexual concerns in women undergoing pelvic surgery and associated treatment for gynecologic cancer. Transl Androl Urol 2015;4:169-85.

27. Tsuburaya A, Nagata N, Cho H, Hirabayashi N, Kobayashi M, Kojima $\mathrm{H}$, et al. Phase II trial of paclitaxel and cisplatin as neoadjuvant chemotherapy for locally advanced gastric cancer. Cancer Chemother Pharmacol 2013;71:1309-14.

28. Avila JG. Pharmacologic treatment of constipation in cancer patients. Cancer Control 2004;11(3, Suppl 1):10-8.

29. Thomas JR, Charles F. Management of dyspnea. J Support Oncol 2003;1:23-32.

30. Sutiawan A. Difference of cervical cancer patients' life quality before and after undergoing paclitaxel cisplatin regimen chemotherapy and BOMP for 3 series in sanglah hospital Denpasar. Thesis. Bukit Jimbaran: Department of Pharmacy Udayana University; 2014.

31. Kornblau S, Catalano R, Champlin RE, Engelking C, Field M, Ippolity C. Management of cancer treatment-related diarrhea: issues and therapeutic strategies. J Pain Symptom Management 2000;19:118-29.

32. Varghese SS, Ram TS, Pavamani SP, Thomas EM, Jeyaseelan V, Viswanathan PN. Concurrent chemo-irradiation with weekly cisplatin and paclitaxel in the treatment of locally advanced squamous cell carcinoma of the cervix: a phase II study. J Cancer Res Ther 2014;10:330-6.

\section{How to cite this article}

- $\quad$ Rini Noviyani, Putu Ayu Indrayathi, I Nyoman Gede Budiana, Ketut Suwiyoga, Ketut Tunas. Assessment of life quality in patients with stage IIB-IIIB squamous cell cervical cancer receiving paclitaxel cisplatin chemotherapy regimen by eortc QLQ-C30 questionnaire in sanglah hospital denpasar. Int J Pharm Pharm Sci 2017;9(5):222-226. 